\title{
2. SEAFLOOR HEAT FLOW ON THE EASTERN FLANK OF THE JUAN DE FUCA RIDGE: DATA FROM "FLANKFLUX" STUDIES THROUGH 1995"
}

\author{
E.E. Davis, ${ }^{2}$ D.S. Chapman, ${ }^{3}$ H. Villinger,${ }^{4}$ S. Robinson, ${ }^{3}$ J. Grigel,${ }^{4}$ A. Rosenberger, ${ }^{4}$ and D. Pribnow ${ }^{3}$
}

\begin{abstract}
A series of geophysical, geochemical, and oceanographic field studies of the sedimented eastern flank of the northern Juan de Fuca Ridge has been conducted to examine the nature and consequences of hydrothermal circulation in young oceanic crust; results provided the framework for drilling during Ocean Drilling Program Leg 168. Definition of the thermal regime in this environment has been the focus of many of these studies, and as a result, a large number of seafloor heat-flow measurements have been completed. We provide a compilation of more than 1000 measurements completed through 1995, including many previously unpublished data as well as new analyses of older published data. The analyses account for probe-penetration depths of all measurements according to the in situ temperatures relative to the local bottom-water temperature. Consistent thermal conductivity/depth structures have been established in two major geographically defined areas by the total of nearly 3000 in situ conductivity measurements. Tables are provided of heat flow and of temperatures and conductivities from which the heatflow values were derived.
\end{abstract}

\section{INTRODUCTION}

The combination of the proximity of the Juan de Fuca Ridge to the North American continental margin and the abundant supply of glacially eroded terrigenous sediment during the Pleistocene has created an environment particularly suitable for studying the thermal structure of young oceanic crust by measuring seafloor heat flow with gravity-driven probes. Reconnaissance heat-flow studies began in the late 1960s (Korgen et al., 1971; Lister, 1970). Some of the early studies in this area led to the hypo that hydrothermal circulation in the igneous oceanic crust was the cause of the large scatter and low average of values relative to those expected if heat were transported by pure conduction from the cooling lithosphere (e.g., Lister, 1972). Detailed studies began in the early to mid-1970s in attempts to resolve the exact nature of variability and to infer patterns and rates of fluid flow in the crust. These included studies over the ridge crest itself, where sediments fill an axial rift valley (Davis and Lister, 1977), as well as on the ridge flank (Davis et al., 1980). Later investigations included a regional transect across Cascadia Basin south of $47^{\circ} \mathrm{N}$ (Moran and Lister, 1987) and detailed measurement arrays in Escanaba Trough, a partially sediment-filled rift valley of the southern Gorda Ridge (Abbott, et al., 1986; Davis and Becker, 1994) and in the Middle Valley sedimented rift of the northern Juan de Fuca Ridge (Davis and Villinger, 1992; Fisher et al., 1996). Attempts have been made recently to extend heat-flow measurements to very thinly sedimented areas using a short probe deployed by a submersible vehicle (Johnson et al., 1993).

The data included in this compilation were collected along a corridor that extends from about $18 \mathrm{~km}$ east of the axis of the Endeavour segment of the Juan de Fuca Ridge at approximately $48^{\circ} \mathrm{N}, 128^{\circ} \mathrm{W}$, to crust nearly $5 \mathrm{Ma}$ in age approximately $140 \mathrm{~km}$ east of the axis (Figs. 1, 2; see also Fig. 5, "Introduction and Summary" chapter,

${ }^{1}$ Davis, E.E., Fisher, A.T., Firth, J.V., et al., 1997. Proc. ODP, Init. Repts, 168: College Station, TX (Ocean Drilling Program).

${ }^{2}$ Pacific Geoscience Centre, Geological Survey of Canada, Box 6000, Sidney, British Columbia V8L 4B2, Canada. davis@pgc.emr.ca

${ }^{3}$ Department of Geology and Geophysics, University of Utah, Salt Lake City, UT 84112, U.S.A.

${ }^{4}$ Fachbereich Geowissenshaften, Universität Bremen, Postfach 330 440, D-28334 Bremen, Federal Republic of Germany. back-pocket foldout). At this location on the eastern Juan de Fuca Ridge flank, the sediment cover that buries the igneous crust is particularly continuous and onlaps the crust at an unusually young age. Measurements were made along local transects of closely spaced heat-flow measurements co-located with seismic reflection profiles to examine fundamental aspects of ridge-flank hydrothermal circulation and lithospheric cooling. Most of these transects strike perpendicular to local seafloor spreading fabric as defined by local seafloor magnetic anomalies and basement structures.

Studies along this corridor began with reconnaissance surveys completed in near-ridge and off-axis environments in 1978 and 1988, respectively. These results, along with those of a joint program to investigate fluid flow through the sediment section and to estimate the composition of basement fluids carried out in 1990, were reported by Davis et al. (1989, 1992). Subsequent studies have concentrated on specific parts of the overall transect to address more thoroughly the objectives outlined below. These studies were carried out as both joint and individual, but coordinated, field observational programs by investigators at the Pacific Geoscience Centre (Geological Survey of Canada), University of Utah, University of Hawaii, University of Bremen, Institute of Ocean Sciences (Department of Fisheries and Oceans Canada), and the Pacific Marine and Environmental Laboratory (National Oceanic and Atmospheric Administration). The field studies have been complemented by numerical modeling of convective heat transport in porous media. Design of the field experiments has also benefited greatly from insights gained from related work carried out in other ridge-flank environments, such as on the flanks of the Costa Rica Rift (Green et al., 1981; Langseth et al., 1988; Fisher et al., 1990; Mottl, 1989; Williams et al., 1974) and the Mid-Atlantic Ridge (Langseth et al., 1984, 1992).

Specific objectives of the work were to (1) determine the efficiency with which sediments blanketing the igneous crust provide a hydrologic barrier to flow, (2) document the distance over which fluid and heat are transported laterally in the upper igneous oceanic crust beneath a relatively impermeable sediment cover, (3) provide constraints on the scale and nature of cellular hydrothermal convection in the upper igneous crust, (4) examine the degree to which flow is stimulated or influenced by buried basement topography and variations in sediment thickness, (5) determine the role of basement outcrops in controlling crustal fluid flow and the advective loss of fluids and heat from the igneous oceanic crust, (6) quantify geochemical 


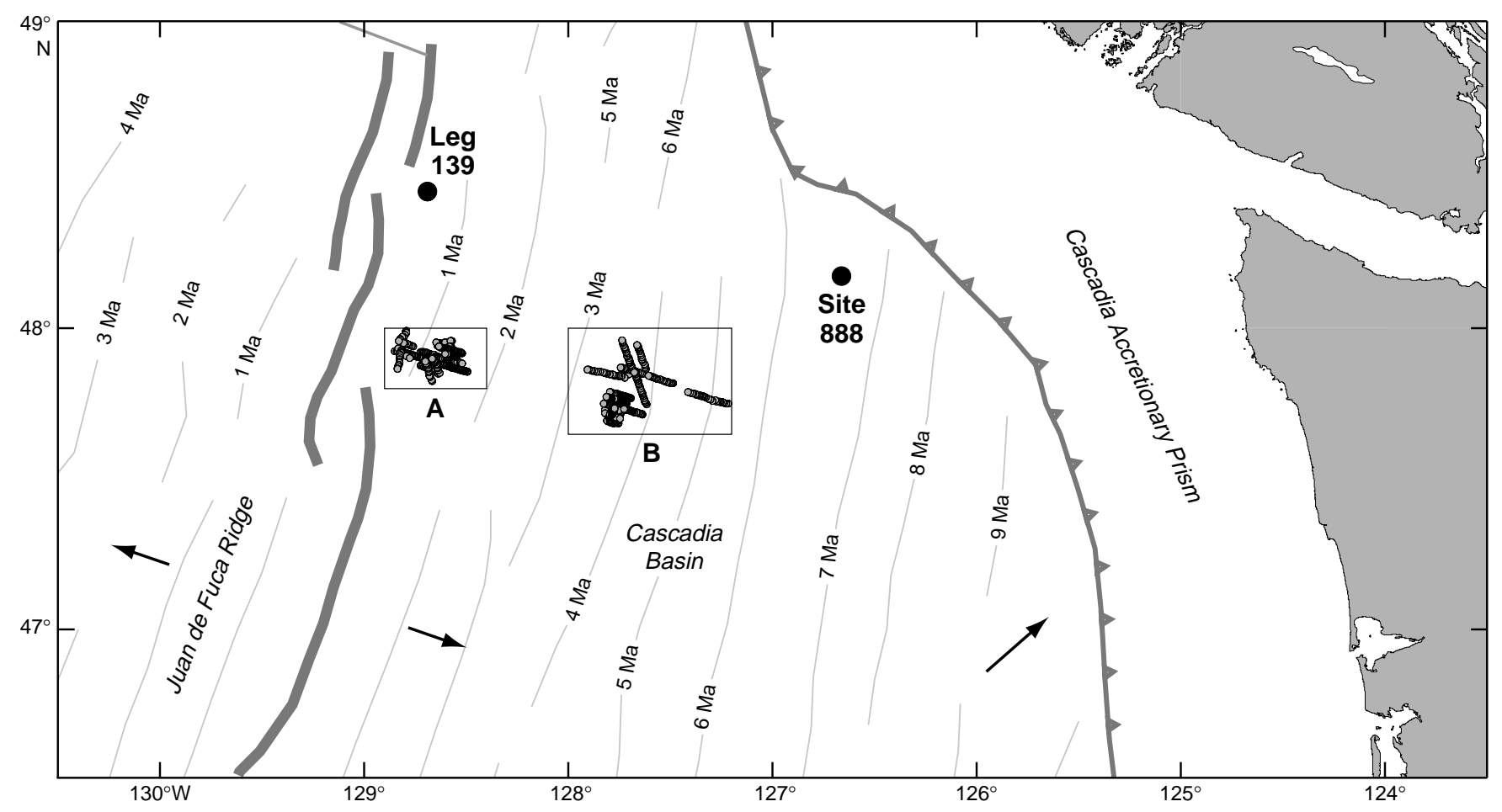

Figure 1. Location map of the FlankFlux study area. Locations of the axis of the Juan de Fuca Ridge and the deformation front of the Cascadia accretionary prism are shown as heavy lines, and directions of relative plate motions across these boundaries are shown by arrows.
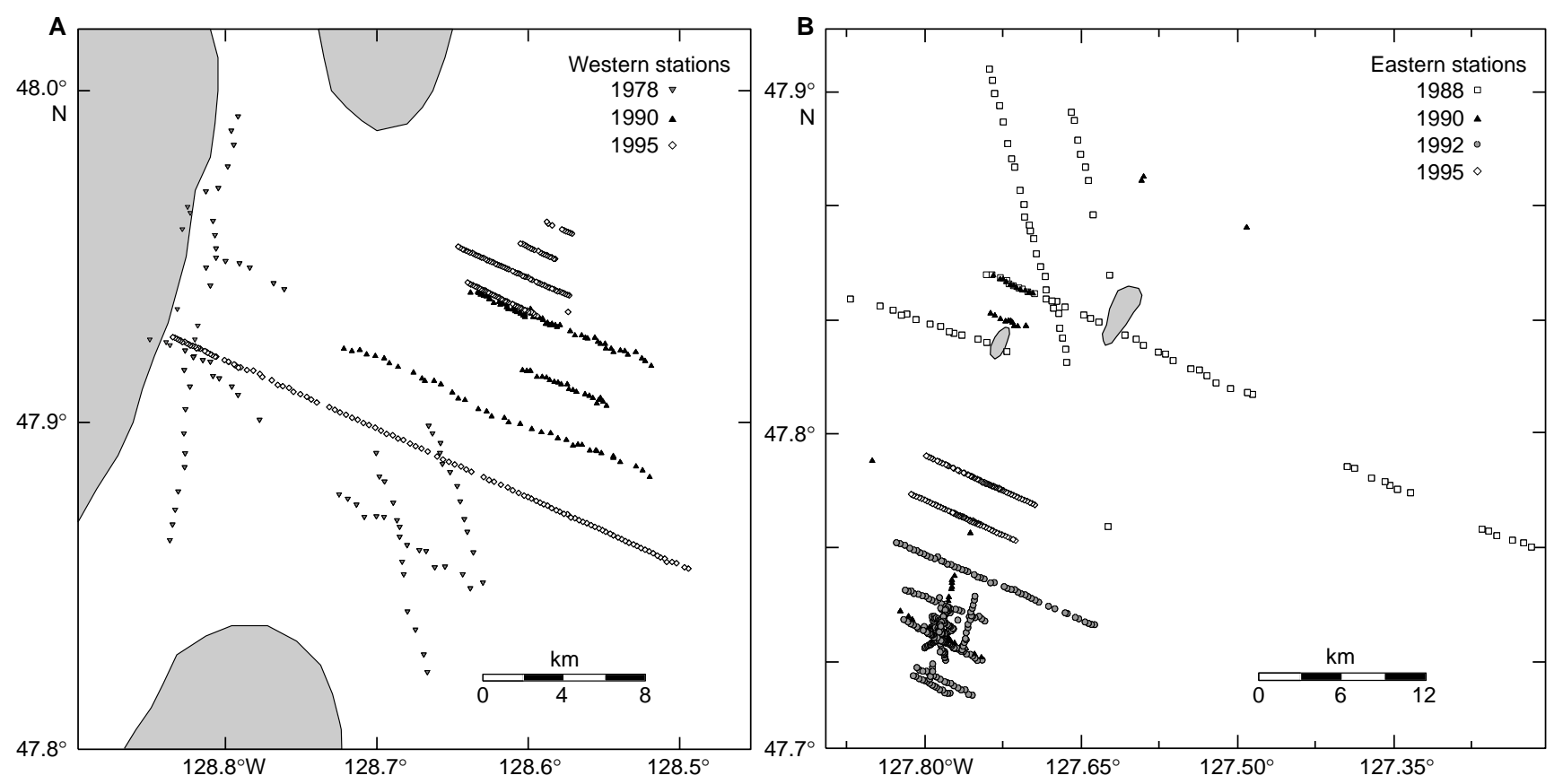

Figure 2. Locations of heat-flow measurements included in Table 1. Locations of the (A) western and (B) eastern areas are indicated on Figure 1. Shading indicates areas of outcropping basement.

fluxes into and out of the crust, and consequently to identify the impact that hydrothermal fluid exchange with the oceans has on global geochemical budgets, and (7) correlate changes in hydrothermal regime to changes in the state of alteration of the crust, including its mechanical consolidation. An additional goal of determining the total heat flow from young lithosphere, through measurements made well away from known outcrops that are potential sites of advective heat exchange with the ocean, has been thwarted at this latitude by what is inferred to be a shallow layer of sand that prevents complete probe penetration. Attempts have been made at several locations between the eastern and western detailed survey areas shown in Figure 2, all without success. 
Following preliminary programs in 1978 and 1988, progressively focused studies continued with coordinated coring, bottom photography, dredging, water-column profiling, and detailed submersible sampling and mapping, all placed in context of basement structure and sediment-thickness variations. Many of the observations and associated modeling studies have been reported previously (Davis and Chapman, 1996; Davis et al., 1989, 1992, 1996, 1997; Fisher and Becker, 1995; M. Mottl, unpubl. data; Rohr, 1994; Thomson et al., 1995; Wang et al., 1997; Wheat and Mottl, 1994). We summarize those results only briefly below; the primary objectives of this report are to provide a description of the way the data were analyzed and an up-to-date compilation of the heat-flow determinations. Except for those collected in 1978, all data have been reprocessed in a consistent manner as described below. Values are presented in tabulated form, along with crustal ages, local sediment thickness where it is well constrained, and the distance of the measurement from the axis of the Juan de Fuca Ridge (Table 1 on CD-ROM, back pocket). A few examples of coincident heat flow and seismic reflection profiles are shown to illustrate the context in which the heat-flow variations occur.

\section{DESCRIPTION OF DATA Navigation}

Because accurate interpretation of marine heat-flow determinations depends strongly on the correspondence with the contextual information provided by seismic reflection data, good navigational control is critical. Navigational control for the surveys described herein varied from cruise to cruise, with the positions of the earliest measurements determined by hyperbolic Loran-C, adjusted to occasional Transit Satellite fixes. Position uncertainties in the 1978 data may be as much as several hundred meters. Significant improvement was realized with the use of range-range Loran-C in 1988, and again in 1990 and 1992 when global positioning system (GPS) navigational control was virtually continuous and reduced uncertainties of ship's position to less than $100 \mathrm{~m}$. The greatest advance in navigational accuracy and operational simplicity was afforded in 1995 through the use of real-time differential GPS (DGPS) navigation, which allowed precise heat-flow station-keeping and seismic shotpoint control.

The greatest uncertainties in the positions of these most recent measurements are associated with the determination of the position of the heat-flow instrument with respect to the ship. Almost all measurements have been made along systematic transects so that the direction from the ship to the instrument was reasonably well constrained. The distance the instrument lagged behind the average motion of the ship could be determined in many instances when structures were crossed that could be identified both with the ship's echo sounder and the record of the acoustic pinger mounted $75 \mathrm{~m}$ above the probe. During typical operations, this distance was 50-100 $\mathrm{m}$, and it is accounted for in the positions given in Tables 1 through 3 (on CD-ROM, back pocket).

With these various sources of error in mind, we would assign navigational uncertainties in the heat-flow measurement positions of about $500 \mathrm{~m}$ to the measurements made in 1978, 100-200 $\mathrm{m}$ to those made in 1988, $100 \mathrm{~m}$ to those made in 1990 and 1992, and 50-100 m to those made in 1995. Greater accuracy was provided by longbaseline acoustic transponder navigation for many of the measurements made in 1992 in the vicinity of the small basement outcrop near $47^{\circ} 43^{\prime} \mathrm{N}, 127^{\circ} 47^{\prime} \mathrm{W}$ (see Fig. 2 and discussion below).

Also included in Table 1 are distances of each measurement from the Endeavour spreading-segment axis of the Juan de Fuca Ridge (assuming a strike direction of $\mathrm{N} 17^{\circ} \mathrm{E}$ ) and basement ages calculated assuming a constant spreading rate of $29.7 \mathrm{~mm} / \mathrm{yr}$ between the Brunhes/Matuyama and Gauss/Gilbert magnetic epoch transitions (with positions determined from sea-surface magnetic anomalies [Currie et al., 1982] and the magnetic time scale of Cande and Kent [1995]; see
Figs. 2, 3, "Introduction and Summary" chapter, this volume). Sediments onlap the topography of the igneous crust at a distance from the ridge of 18.6 km (see Fig. 2; also see Fig. 7, "Introduction and Summary" chapter, this volume).

\section{Seismic Reflection Profiles}

Nearly all heat-flow measurements have been collected along seismic reflection profiles that constrain local basement structure and sediment thickness. Seismic data collected before 1995 were either recorded in analog format or lack sufficient navigational control to be migrated; none is shown here. Most of those data were collected using a 0.65 -L $\left(40-\mathrm{in}^{3}\right)$ airgun source. Data collected in 1995 were collected using a 1.5-L $\left(90-\mathrm{in}^{3}\right)$ Generator-Injector gun source and a digital acquisition and processing system operated by the University of Bremen. The gun was supplied with compressed air at 1700 psi pressure and was fired under DGPS control at 25-m shot spacing at nominally 10-s intervals. Data were acquired digitally with 20-bit floating point resolution at $6-\mathrm{kHz}$ sampling frequency then low-pass filtered and resampled at $2 \mathrm{~ms}$ for recording to provide a $250 \mathrm{-Hz}$ frequency range. A linear-ramp gain was applied to the data for plotting, and all records were migrated using a velocity profile adapted from Rohr (1994). The acquisition system was developed and operated by the University of Bremen.

Correspondence between heat-flow and seismic data is provided in Table 1 wherever heat-flow measurements fall within about $100 \mathrm{~m}$ of any of the 1995 reflection profiles. This includes all heat-flow measurements made in 1995, as well as many made previously. Seafloor reflection-point positions were determined for each shotpoint using the relative offsets between the GPS receiver antenna, the seismic source, and the midpoint of the receiver array.

Two-way traveltime depths to the seafloor and to the basement surface have been picked from all migrated seismic data. For those heat-flow measurements that were made along these profiles, the twoway times are included in the table. Conversions from traveltime to sediment thickness and basement depth can be made using velocitydepth functions determined at nearby sites such as at Site 888 and those drilled during ODP Leg 139 (e.g., Davis and Fisher, 1994; see Fig. 1), although the accuracy of conversion can be improved greatly using the site-specific information provided in this volume.

\section{Heat-Flow Data}

Much of the reason for recent success in resolving details of seafloor heat-flow variability, which often occurs on a scale of a few hundred meters or less, has been the development of probes that allowed extended deployments with multiple, closely spaced penetrations (Lister, 1979; Hyndman et al., 1979). The probes used for the measurements reported here all follow the design of Lister (1979); they represent three generations of instruments that are fundamentally the same, differing only in ways that have improved the mechanical robustness of the instruments and the dynamic range, resolution, and absolute accuracy with which temperature gradients and conductivities are measured in situ. The instrument employed for measurements in the earliest survey (1978) included a 2.5-m-long probe having seven thermistors. More recent data were collected with 2.5- and 5-m- (1988) and 3.5-m-long probes (1990 and later) containing 11 thermistors. Other improvements included measurement of uni-axial (1988) and bi-axial tilt (1995), high-resolution pressure (1988), rapidresponse bottom-water temperature (1988), and the use of ultra-stable $\mathrm{a} / \mathrm{d}$ conversion (1995). The most recent improvements have permitted repeatability to $1 \mathrm{mK}$, a maximum resolution of $0.6 \mathrm{mK}$, and a dynamic range of $50 \mathrm{~K}$. The physical configuration of the instrument has remained unchanged since 1988 and is shown in Figure 3.

Although the data included in this report have been collected over a span of $17 \mathrm{yr}$, the essential characteristics are common to all. A typical penetration record is illustrated in Figure 4A. The probe is often 


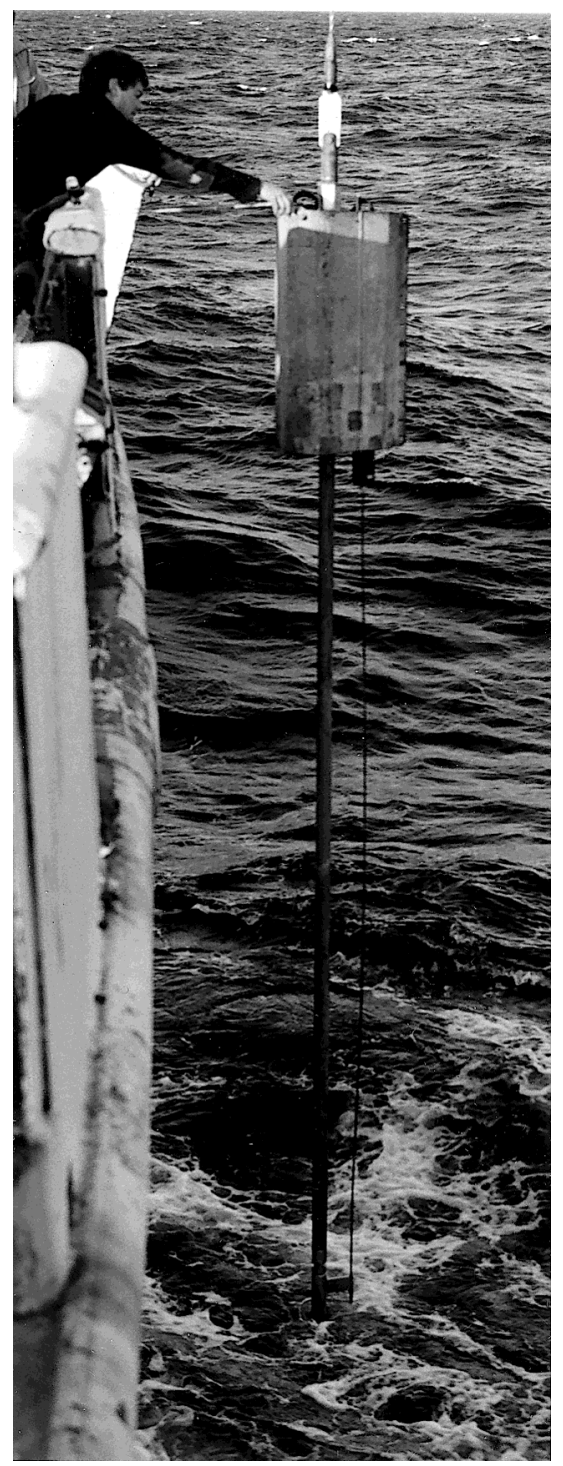

Figure 3. Photograph of marine heat-flow instrument used in recent Juan de Fuca Ridge flank studies. The 4-m-long, 6-cm-diameter strength member supports an 8-mm-diameter sensor string that houses a heater wire and a 3-mlong chain of 11 thermistors. The instrument is driven into the seafloor with an $800-\mathrm{kg}$ weight stand that houses the electronics and power supply for data logging, heat-pulse control, and low-resolution data telemetry.

raised and lowered slowly through the water column between penetrations to document the thermal structure of the water column (e.g., Thomson et al., 1995). At some point in the near-bottom water that is known to be effectively isothermal (less than $1 \mathrm{mK}$ over the depth interval spanned by the length of the sensor), the probe is held stationary to provide a relative calibration of the thermistors, including the bottom-water thermistor. Following penetration, temperatures are typically monitored for $7 \mathrm{~min}$ (approximately 10 thermal time constants of the 8-mm-diameter sensor) to allow accurate extrapolation of the penetration transients generated by the difference between the temperature of the probe when it comes to rest and the surrounding sediment (Fig. 4B). This difference can be either positive or negative, depending on the amount of frictional heating generated during penetration relative to the temperature difference between the formation at any given depth and the temperature of the probe immediately pri- or to penetration (i.e., that of bottom water). After this equilibration period, a metered pulse of heat $(600 \mathrm{~J} / \mathrm{m})$ is generated along the length of the probe; the temperature rise and rate of decay following this pulse (Fig. 4B) permits the thermal conductivity to be determined (Fig. 4C), following the method proposed by Lister (1979). The complete data reduction scheme is described in detail by Villinger and Davis (1987). Depths of penetration, and hence vertical positions of each temperature and conductivity value, were determined from plots of temperature as a function of integrated sediment thermal resistance, in particular from the temperature of the uppermost thermistor that penetrates sediment relative to bottom water measured by the water-temperature thermistor at the top of the weight stand Fig. 4C).

Because of power limitations and attempts to optimize operation time, and sometimes because operational difficulties caused early physical disturbances or required early pullouts, thermal conductivity was measured at about one-third of all penetrations. For this reason, and because the largest conductivity variability is associated with the contrast between muds and occasional thin turbidite sand layers at a very small depth scale (typically a few centimeters thick in the upper few meters of sediment), conductivity data were combined to establish an average conductivity structure. Data were divided into two geographically defined groups; finer distinctions were not justified by any systematic differences in the conductivity data with the exception of six measurements at the eastern end of Station 95-08 (see discussion at the end of this section). Conductivities for all penetrations and for each geographical group are shown as functions of depth in Figure 5. The western and eastern groups are clearly distinct; the difference is probably associated with subtle differences in porosity, which could be associated with differences in average grain size or degree of sorting, and possibly in lithology, caused, for example, by differences in quartz content, a mineral constituent having a particularly high thermal conductivity.

On average, the conductivity in the western area is higher than that in the eastern area, and high peak values are present in both areas. The high values are associated with layers of sand, as there is often large frictional heating associated with them. The layers are inferred to be thin, less than the $30-\mathrm{cm}$ spacing of the thermistor sensors, on the basis of two observations: (1) The high conductivities are usually limited to single values as seen in Figures 6 and 7; conductivities immediately above and below are usually not displaced from the background trend; and (2) local temperature gradients above and below high-conductivity layers are found to be displaced by amounts that require thicknesses of high-conductivity material that range from 5 to $15 \mathrm{~cm}$ (Robinson, 1997). The material of these layers often appears to be mobilized by penetration of the probe, as temperatures determined at their depths commonly lie off the general trend defined by the temperatures of other thermistors, and the corresponding frictional decays often do not follow ideal cylindrical decay theory.

Although many deviations from the average trends shown in Figure 5 do not appear to be systematic, some exceptions occur where anomalies in the conductivity structure associated with a locally coherent layer can be followed for some distance. Illustrations of this are shown in Figure 6, where anomalous conductivity (relative to the average conductivity profile) is shown for a pair of stations. The plot serves to illustrate three important points: (1) As discussed above, anomalous conductivity is confined to discrete thin layers. (2) There appear to be no detectable differences between conductivities measured during different cruises, often with different instruments. This is addressed more specifically in Figure 7, where pairs of measurements made close to one another but at different times are compared. (3) The high-conductivity layers are sometimes coherent over distances of several kilometers, and in the western area, they make a clear and coherent contribution to the average conductivity structure (Fig. 5B).

Attempts were made to incorporate these details into locally defined thermal conductivity structures, but with little success in the way of improving either the quality of individual temperature vs. cu- 

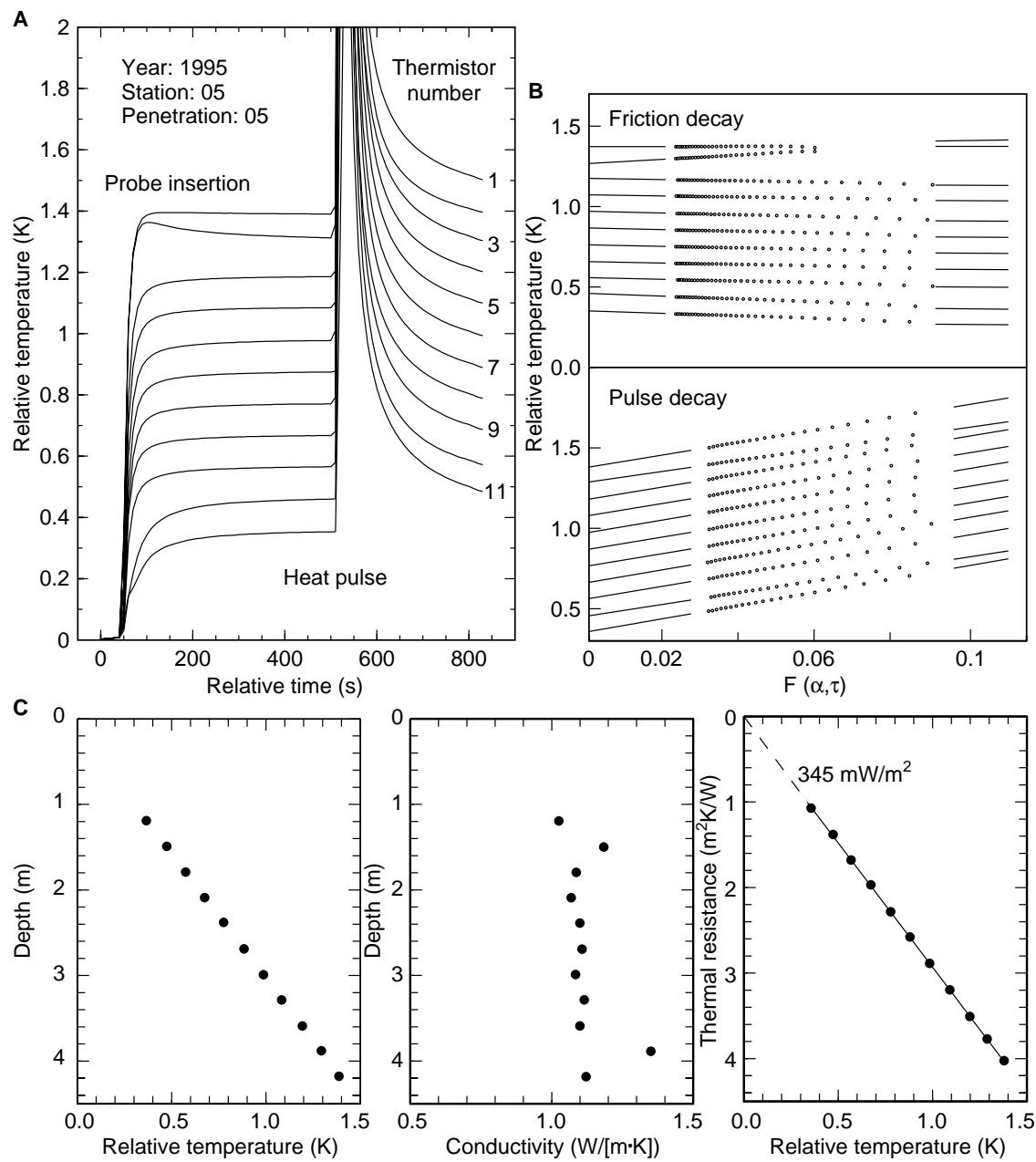

Figure 4. A. Heat-flow penetration record showing temperature rises at the time of penetration and at the time the calibrated 20-s-long heat pulse is fired. Data are sampled at 10-s intervals. Anomalous frictional heating is evident at the level of thermistor 10 (numbered from the bottom), and the thermal conductivity computed at that level (see C) is anomalously high. B. Temperatures, relative to bottom-water temperature, of frictional and heat-pulse decays, plotted against parameterized time (see Villinger and Davis, 1987), used to calculate in situ temperatures and thermal conductivities. C. Temperature vs. depth, conductivity vs. depth, and temperature vs. integrated thermal resistance, calculated from the raw data shown in A.

mulative thermal resistance (Bullard) fits or the coherency of local heat-flow variations. For these reasons, the average conductivity structures for the eastern and western areas were used for all heatflow calculations in each area, with regression fits done through temperatures plotted against the site-average cumulative thermal resistance. The two conductivity/depth functions used are shown in Figure $5 \mathrm{~B}$ and $5 \mathrm{C}$; they are simply smooth polynomials fitted through harmonic mean conductivities computed for all data using $10-\mathrm{cm}$ depth intervals. The heat-flow values thus derived are included in Table 1 (on CD-ROM, back pocket). All temperature data are given in Table 2 (on CD-ROM, back pocket), and all conductivity data are given in Table 3 (on CD-ROM, back pocket).

As mentioned above, there is one group of measurements where conductivities are systematically and significantly different (13\% higher on average) than the average structure for the bulk of the western area. These lie at the eastern end of Station 95-08 (penetrations 95-08-02 through -27 , east of $128.55^{\circ} \mathrm{W}$ longitude; see Fig. $2 \mathrm{~A}$ ) in a sedimentary distributary system that is distinct from the one that supplies sediment to the area farther west. Heat-flow values for these penetrations have been computed on the basis of the local average conductivity structure defined by the six penetrations of that group where conductivities were measured (see Table 3 on CD-ROM, back pocket).

\section{Errors}

Sources of errors can be grouped into four categories. These are discussed separately as follows:

1. Measurement errors: The smallest errors are those associated with the actual determinations of temperature and conductivity at each thermistor. Extrapolated temperatures are normally resolved to better than a few $\mathrm{mK}$, and conductivities are determined to within about $1 \%$. These uncertainties contribute little to the uncertainty of the heat-flow determinations, except in unusual cases where physical disturbances cause non-ideal decays. Highly disturbed penetrations have been eliminated from the data set. Most heat-flow values, calculated as the slope of the linear regression of temperature vs. integrated thermal resistance, are determined with an uncertainty at the $95 \%$ confidence level of less than $1 \%$.

2. Details of lithology: Perhaps the greatest source of uncertainty arises from the incomplete knowledge of the thermal conductivity structure arising from variations in sediment lithology and porosity over the measurement intervals. The preliminary analysis discussed above suggests that high-conductivity layers are thin. By using the regional harmonic mean conductivity structure, we have assumed that their contribution is correctly represented by the large number of pen- 


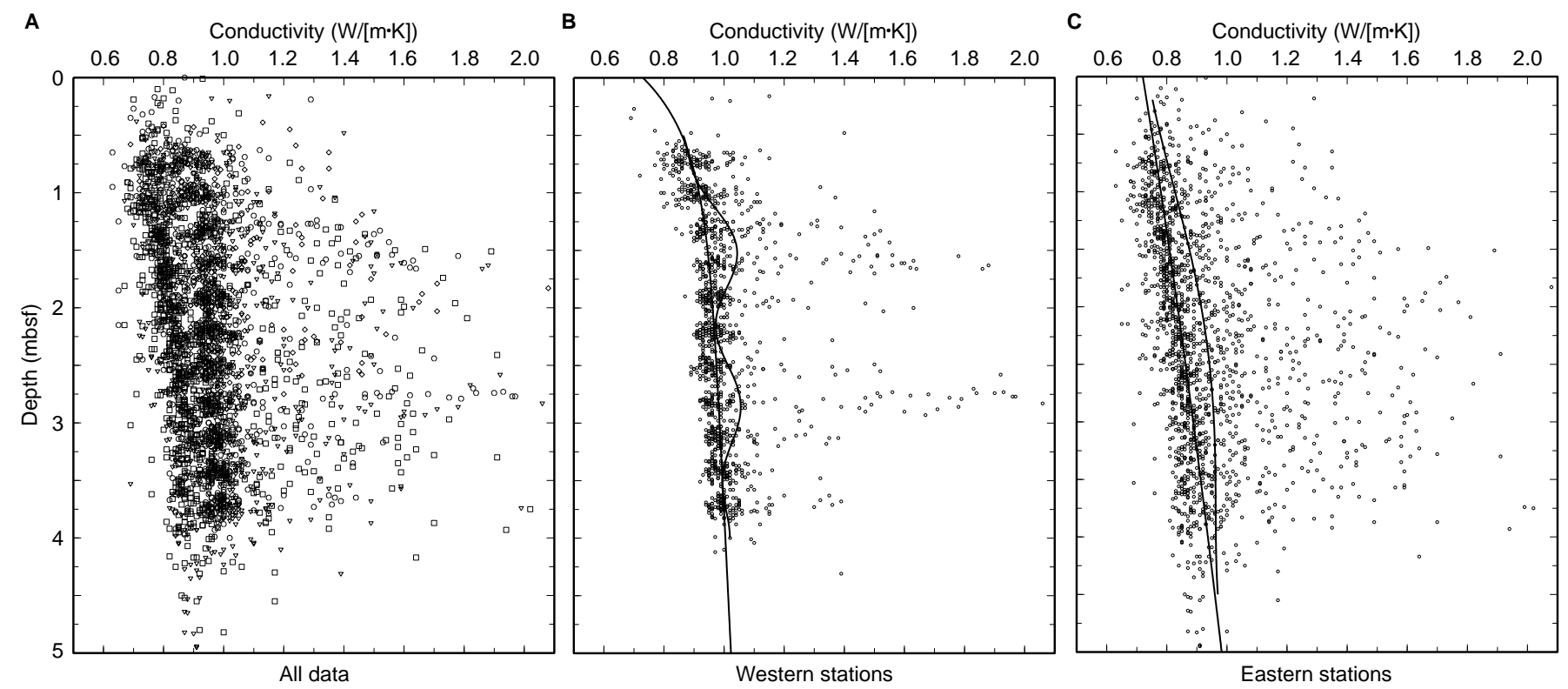

Figure 5. Thermal conductivity plotted against depth for $(\mathbf{A})$ all measurements and for the $(\mathbf{B})$ western and $(\mathbf{C})$ eastern groups of measurements shown in Figure 2 (see Table 3). The lower smooth curves (referred to as the "mudlines") are fitted through the highest density of points and ignore all high values believed to be associated with layers of sand (those greater than $0.2 \mathrm{~W} /[\mathrm{m} \cdot \mathrm{K}]$ above the lower bounds of conductivities). The higher curves are computed as a smooth harmonic mean of all values and are used to compute the heat-flow values given in Table 1.

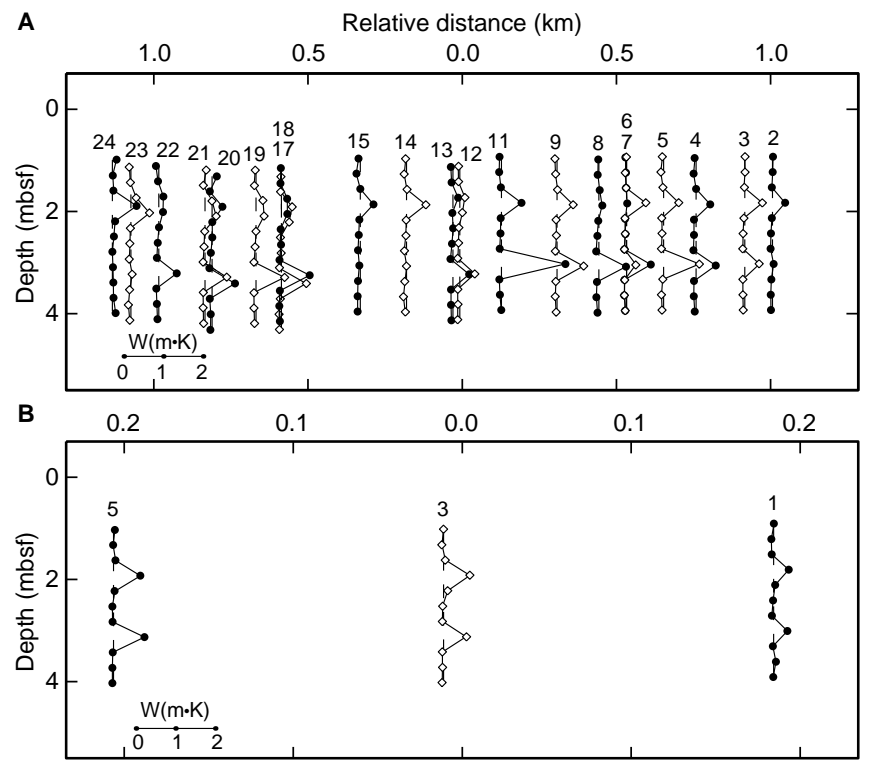

Figure 6. Anomalous thermal conductivity (measured values $=$ points) relative to the "mudline" (dashed lines; see Fig. 5B) for penetrations along heatflow Stations (A) 90-33 and (B) 95-04 in the western part of the ridge-flank corridor where layers of anomalous conductivity are particularly continuous. Stations 90-33 and 95-04 are separated by about $3 \mathrm{~km}$, and the distance covered by Station 90-33 is about $2 \mathrm{~km}$. Solid circles and open diamonds distinguish alternate penetrations along the station transects.

etrations. A minimum, but unreasonably low, thermal conductivity structure might be taken as the "mudline" profile for each of the areas. An upper limit of the heat flow would be derived by using the conductivities measured at each penetration and by assuming that each thermistor had sampled a layer equivalent in thickness to the

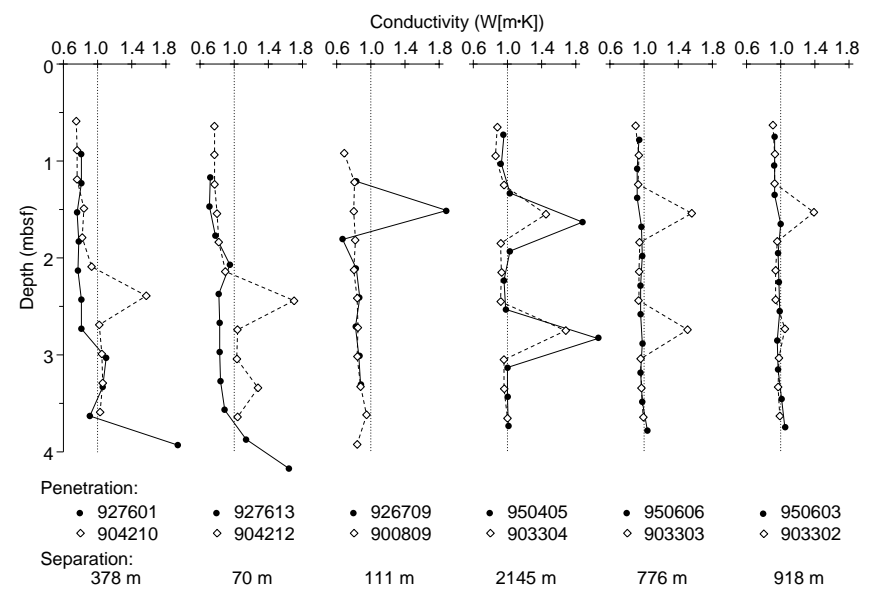

Figure 7. Thermal conductivity measured at proximate pairs of penetrations made during different years. Separations of the measurements are given.

thermistor spacing. Reasons for why this is unreasonable are given above.

3. Penetration depth: Any uncertainty in the penetration depth contributes error to the heat flow because of the general increase of conductivity with depth that is probably associated with compaction (Fig. 5). The increase with depth is greater in the eastern area; there, a $1-\mathrm{m}$ uncertainty in penetration depth translates into a $6 \%$ error in average conductivity and, thus, heat flow. Actual penetration depth uncertainties are probably only a few tens of centimeters. This is attested to by the clustering of points in the conductivity/depth plots, particularly in the western area. This clustering demonstrates that, in this area, the nature of the bottom caused the instrument to stop at a consistent depth from penetration to penetration and that the depths of penetration are very well determined using the temperature vs. thermal resistance and water-temperature data. 


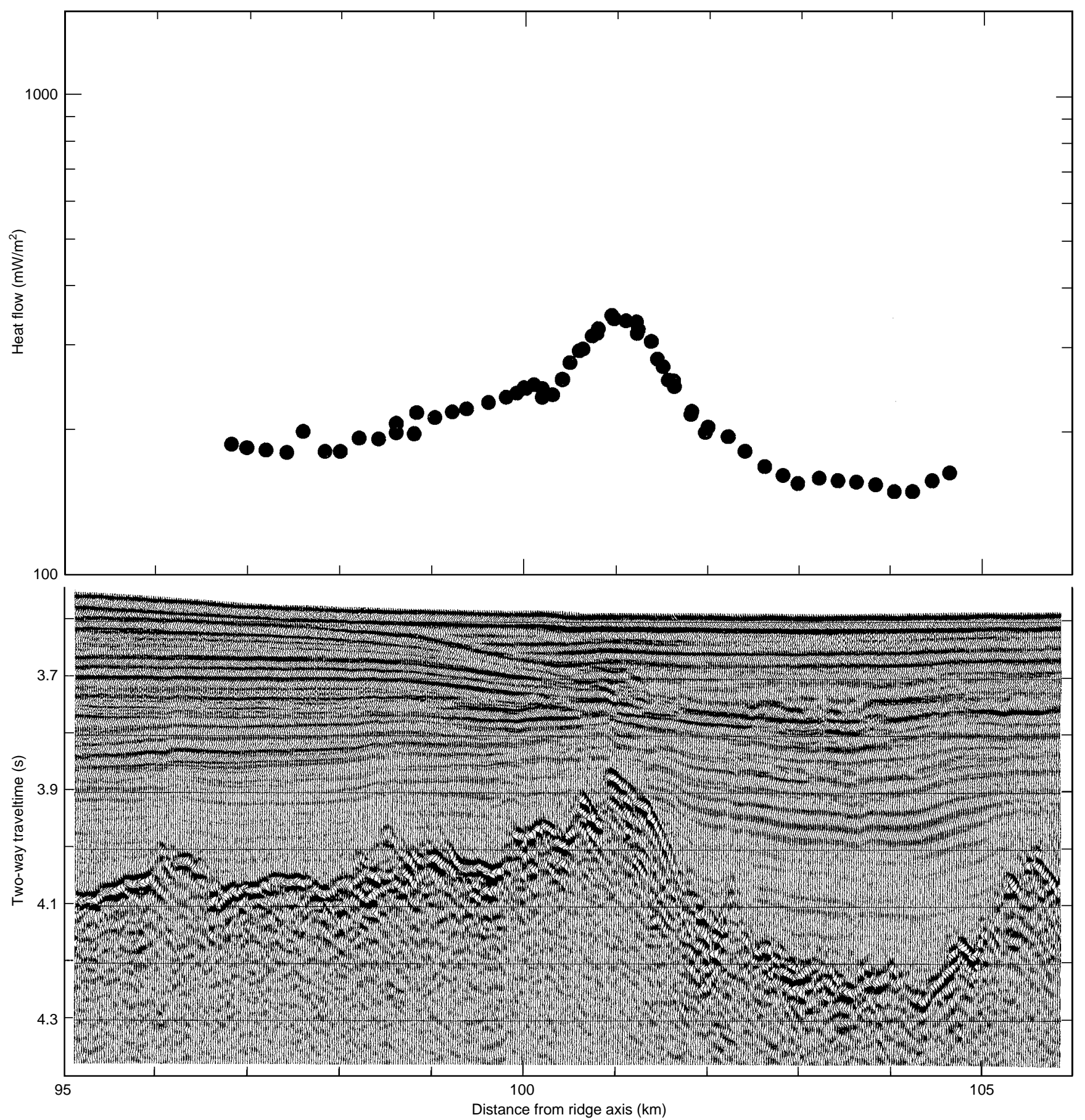

Figure 8. Seismic reflection profile and co-located heat-flow transect across a buried basement ridge. The coherent heat-flow variability is inferred to be caused by efficient lateral hydrothermal transport in the upper igneous crust, which causes the top of basement to be nearly isothermal. Depths below seafloor in kilometers are slightly less than local two-way traveltime in seconds; sediment velocities range from about $1.5 \mathrm{~km} / \mathrm{s}$ just below the seafloor to about $1.8 \mathrm{~km} / \mathrm{s}$ at a depth of $500 \mathrm{mbsf}$.

4. Tilt: The uni-axial tilt sensor used for measurements collected from 1988 to 1992 provides only a lower limit of total instrument tilt. The sensor was usually oriented to measure tilt in the plane passing through the strength member and the sensor string. Tilts are normally caused by excessive horizontal velocity of the probe during penetration, and because of the dynamics of the instrument, which hangs on a swivel, the tilts should normally fall along this plane. Thus, the measured values probably provide reasonable estimates of the total tilt, despite being not absolutely accurate. Penetrations having tilts greater than about $7^{\circ}$ have been eliminated from the compilation. These measurements commonly displayed non-ideal behavior indicative of physical disturbances. 


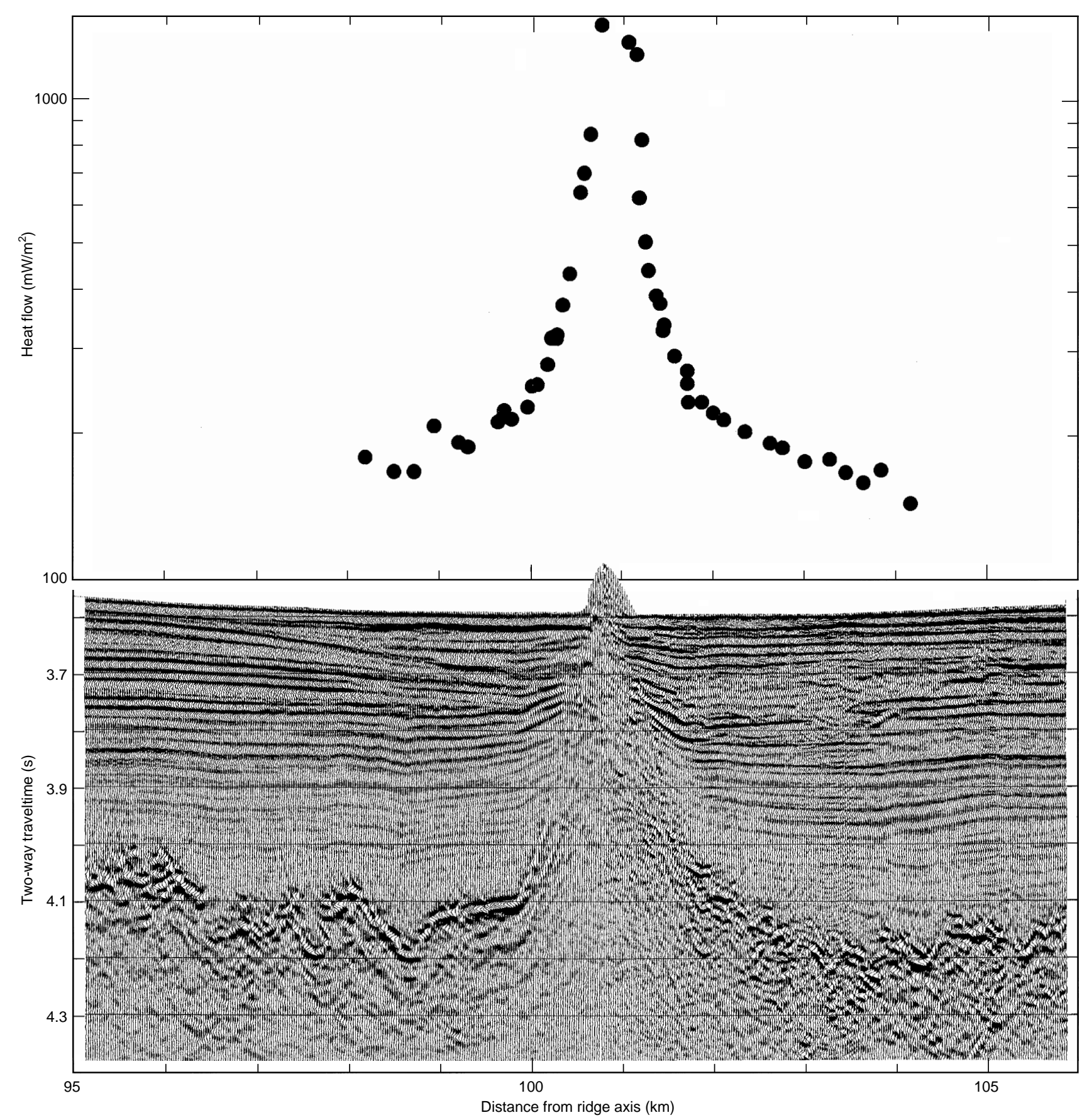

Figure 9. Seismic reflection profile and co-located heat-flow transect crossing small igneous basement outcrop where diffuse and focused hydrothermal ventilation occurs. The increase in heat flow approaching the outcrop is inferred to reflect the rapid ascent of water along the basement/sediment interface.

\section{SUMMARY OF PRINCIPAL CONCLUSIONS}

Much has been learned through the surface ship and submersible studies carried out along this transect to date. The heat-flow data reported here have provided and are providing critical constraints for hypotheses and quantitative models of hydrothermal circulation on flanks of ocean ridges, and they were critical for locating drilling sites for Leg 168.

Inferences, including both those made on the basis of the heatflow data reported here and on the basis of many other geophysical, geochemical, and oceanographic observations, are summarized as follows:

1. Fluid circulation in the upper oceanic crust appears to be sufficiently vigorous to homogenize temperatures and fluid compositions over distances of several kilometers, despite large variations in sediment thickness (Davis et al., 1989, 1992; M. Mottl, unpubl. data; Wheat and Mottl, 1994). This homogenization is well illustrated at several locations by the clear correlation between heat flow and buried basement topography, with the fundamental relationship being a 
simple inverse one between heat flow and the total thermal resistance of the sediment section (Fig. 8).

2. The low-permeability, clay-rich turbidite sediments that bury the igneous crust in this region are very effective in forming a hydrologic seal. With the relatively small pressure gradients created by thermal buoyancy, fluid flow is reduced to rates that are thermally insignificant by sediment only a few tens of meters thick and to rates that are geochemically insignificant by sediment less than about 150 $m$ thick (Wheat and Mottl, 1994; Snelgrove and Forster, 1996).

3 . Fluid flow is strongly affected by the presence of basement topography (Fisher and Becker, 1995; Wang et al., 1997). The inferred degree of homogenization of upper basement fluid temperatures provides a strong constraint on the heat transport efficiency (Nusselt number) and the permeability of the uppermost igneous crust. Values are required to be very high, many factors higher than those observed to date in boreholes that penetrate the upper oceanic crust, suggesting that the properties that control flow at the full scale of the formation are not represented at the scale of a borehole (Davis et al., 1997).

4. Attempts to image the planform and scale of cellular hydrothermal convection in the igneous crust, and hence the penetration depth of thermally significant circulation, have been frustrated by the strong control that sediment thickness variations exert on local seafloor heat-flow variations, by the strong control that basement topography and other hydrologic heterogeneity, such as that produced by fault zones (Yang et al., 1996), exert on fluid flow, and by the lack of sites where basement topography and sediment thickness variations are absent. An excellent candidate for imaging cellular circulation was thought to have been found in one small area along the transect described here (Davis et al., 1996), but close inspection of recent seismic profiles has shown that the subtle heat-flow variations that were first interpreted to reflect the pattern of cellular convection may be associated with intracrustal permeability structure (Davis and Chapman, 1996). Furthermore, the modeling results described above (Wang et al., 1997; Davis et al., 1997) suggest that convection in the upper crust may occur at such a high Rayleigh number that convection is chaotic and, thus, that it may not be possible to use seafloor heat-flow measurements to image temperature variations associated with cellular circulation, given the thermal time constant of a few hundred meters of sediment.

5. Isolated outcrops of igneous basement rock serve efficiently as hydrothermal "chimneys." The potential for fluid flow is provided by the high permeability of the igneous rocks that penetrate the sediment section. The driving force must be provided by the thermal buoyancy created by the contrast between the average conditions in the section surrounding the outcrops (where fluid densities are established at a conductive geotherm) and the warm conditions created by the upflow in the crust beneath the outcrops themselves. This flow is manifest in elevated conductive heat flow in the immediate vicinity of and over the outcrops (e.g., Fig. 9; Davis et al., 1989, 1992; M. Mottl, unpubl. data) and in both diffuse and focused fluid flow through the outcrops that is evident in the geochemistry of sediment pore fluids (Davis et al., 1992; Wheat and Mottl, 1994; M. Mottl, unpubl. data), in warm springs at the seafloor (M. Mottl, unpubl. data), and in thermal, geochemical, and light-attenuation anomalies in the water column (Thomson et al., 1995).

6. Whereas there is a clear tendency for fluids to rise and discharge through the seafloor at small isolated outcrops that are kept ubiquitously and perpetually warm by virtue of their small size and the consequent degree of focusing of flow, areas of extensive igneous outcrop can host both discharge and recharge and are, thus, extensively cooled by circulation of seawater. Effects of open circulation appear to be felt over distances of a few to many tens of kilometers by lateral heat and fluid transport in the upper igneous crust beneath areas sealed by relatively impermeable sediment (e.g., Fig. 10; Sclater et al., 1976; Baker et al., 1991; Davis et al., 1992; Langseth and Herman, 1981), although the details of this transport are not well un- derstood. Heat transport could take place via highly efficient local mixing of convecting basement water or by lateral advection driven by regional pressure gradients created by buoyancy forces.

7. Seismic velocities of the uppermost igneous crust increase systematically eastward from the region of outcropping basement over a distance of a few tens of kilometers (Rohr, 1994). This increase is inferred to be associated with the transition from open to sedimentsealed hydrothermal conditions and the associated mineralization that cements fractures and other voids in the rock.

We anticipate that a quantum jump in our understanding of the physical and chemical fluid flow processes in this ridge-flank environment will be realized through the efforts of ODP Leg 168 and that many of these inferences will be confirmed, modified, or quantified. We also hope that additional analyses of the heat-flow data reported here will continue to provide new insights into lithospheric cooling and ridge-flank hydrothermal processes.

\section{ACKNOWLEDGMENTS}

Many people have provided technical and scientific help with the various cruises to the Juan de Fuca Ridge flank and with the associated navigation and data processing. In particular, we would like to thank R. Macdonald, R. Currie, M. Bone, R. Meldrum, W. Bentkowski, R. Harris, C. Forster, S. Putnam, and D. Pribnow. Much of the labor of the data reprocessing and the generation of Tables 1 through 3 (on CD-ROM, back pocket) was shouldered by S. Robinson; that work is described in detail in Robinson (1997). Operations have been supported by the captains, officers, and crews of the research vessels J.P. Tully and the Parizeau. Funding for various phases of the FlankFlux program has been provided by the Geological Survey of Canada, the National Science Foundation, the Bundesministerium für Bildung, Wissenschaft, Forschung, und Technologie (Project No. 03g052A in 1995), and by Joint Oceanographic Institutions, Inc.

\section{REFERENCES}

Abbott, D.H., Morton, J.L., and Holmes, M.L., 1986. Heat-flow measurements on a hydrothermally active, slow-spreading ridge: the Escanaba Trough. Geophys. Res. Lett., 13:678-680.

Baker, P.A., Stout, P.M., Kastner, M., and Elderfield, H., 1991. Large-scale lateral advection of seawater through oceanic crust in the central equatorial Pacific. Earth Planet. Sci. Lett., 105:522-533.

Cande, S.C., and Kent, D.V., 1995. Revised calibration of the geomagnetic polarity timescale for the Late Cretaceous and Cenozoic. J. Geophys. Res., 100:6093-6095.

Currie, R.G., Seemann, D.S., and Riddihough, R.P., 1982. Total magnetic field anomaly, offshore British Columbia. Open File Rep.-Geol. Surv. Can., 828.

Davis, E.E., and Becker, K., 1994. Thermal and tectonic structure of the Escanaba Trough: new heat-flow measurements and seismic-reflection profiles. In Moreton, J., Zierenberg, R.A., and Reiss, C.A. (Eds.), Geologic, Hydrothermal, and Biologic Studies at Escanaba Trough, Gorda Ridge, Offshore Northern California. U.S. Geol. Surv. Bull., 2022:4564.

Davis, E.E., and Chapman, D.S., 1996. Problems with imaging cellular hydrothermal convection in oceanic crust. Geophys. Res. Lett., 23:35513554.

Davis, E.E., Chapman, D.S., and Forster, C.B., 1996. Observations concerning the vigor of hydrothermal circulation in young oceanic crust. J. Geophys. Res., 101:2927-2942.

Davis, E.E., Chapman, D.S., Forster, C.B., and Villinger, H., 1989. Heatflow variations correlated with buried basement topography on the Juan de Fuca ridge flank. Nature, 342:533-537.

Davis, E.E., Chapman, D.S., Mottl, M.J., Bentkowski, W.J., Dadey, K., Forster, C., Harris, R., Nagihara, K., Rohr, K., Wheat, G., and Whiticar, M.J., 
1992. Flankflux: an experiment to study the nature of hydrothermal circulation in young oceanic crust. Can. J. Earth Sci., 29:925-952.

Davis, E.E., and Fisher, A.T., 1994. On the nature and consequences of hydrothermal circulation in the Middle Valley sedimented rift: inferences from geophysical and geochemical observations, Leg 139. In Mottl, M.J., Davis, E.E., Fisher, A.T., and Slack, J.F. (Eds.), Proc. ODP, Sci. Results, 139: College Station, TX (Ocean Drilling Program), 695-717.

Davis, E.E., and Lister, C.R.B., 1977. Heat flow measured over the northern Juan de Fuca Ridge: evidence for widespread hydrothermal circulation in a highly heat-transportive crust. J. Geophys. Res., 83:4845-4860.

Davis, E.E., Lister, C.R.B., Wade, U.S., and Hyndman, R.D., 1980. Detailed heatflow measurements over the Juan de Fuca Ridge system. J. Geophys. Res., 85:299-310.

Davis, E.E., and Villinger, H., 1992. Tectonic and thermal structure of the Middle Valley sedimented rift, northern Juan de Fuca Ridge. In Davis, E.E., Mottl, M.J., Fisher, A.T., et al., Proc. ODP, Init. Repts., 139: College Station, TX (Ocean Drilling Program), 9-41.

Davis, E.E., Wang, K., He, J., Chapman, D.S., Villinger, H., and Rosenberger, A., 1997. An unequivocal case for high Nusselt-number hydrothermal convection in sediment-buried igneous oceanic crust. Earth Planet. Sci. Lett., 146:137-150.

Fisher, A.T., and Becker, K., 1995. Correlation between seafloor heat flow and basement relief: observational and numerical examples and implications for upper crustal permeability. J. Geophys. Res., 100:12641-12657.

Fisher, A., Becker, K., Narasimhan, T.N., Langseth, M.G., and Mottl, M.J., 1990. Passive, off-axis convection on the southern flank of the Costa Rica Rift. J. Geophys. Res., 95:9343-9370.

Fisher, A.T., Langseth, M., Baker, P., Ryan, W., Iturrino, G., Jin, W., Cramer, B., Schultheiss, P., Darlington, E., Zierenberg, R., Goodellow, W., Stein, J., Daniel, D., Glenn, S., Grove, M., and Conly, A., 1996. Fine-scale variations in heat and fluid flow at a sedimented spreading center: areas of active venting in Middle Valley, Northern Juan de Fuca Ridge. Eos, 77:S256.

Green, K.C., Von Herzen, R.P., and Williams, D.L., 1981. The Galapagos spreading center at $86^{\circ} \mathrm{W}$ : a detailed geothermal field study. J. Geophys. Res., 86:979-986.

Hyndman, R.D., Davis, E.E., and Wright, J.A., 1979. The measurement of marine geothermal heat flow by a multipenetration probe with digital acoustic telemetry and in-situ thermal conductivity. Mar. Geophys. Res., 4:181-205.

Johnson, H.P., Becker, K., and Von Herzen, R.P., 1993. Near-axis heat flow measurements on the northern Juan de Fuca Ridge: implications for fluid circulation in the crust. Geophys. Res. Lett., 20:1875-1878.

Korgen, B.J., Bodvarsson, G., and Mesecar, R.S., 1971. Heat flow through the floor of the Cascadia Basin. J. Geophys. Res., 76:4758-4774.

Langseth, M.G., Becker, K., Von Herzen, R.P., and Schultheiss, P., 1992. Heat and fluid flux through the sediment on the western flank of the MidAtlantic Ridge: a hydrological study of North Pond. Geophys. Res. Lett., 19:517-520.

Langseth, M.G., and Herman, B.M., 1981. Heat transfer in the oceanic crust of the Brazil Basin. J. Geophys. Res., 86:10805-10819.

Langseth, M.G., Hyndman, R.D., Becker, K., Hickman, S.H., and Salisbury, M.H., 1984. The hydrogeological regime of isolated sediment ponds in mid-ocean ridges. In Hyndman, R.D., Salisbury, M.H., et al., Init. Repts. DSDP, 78 (Pt. 2): Washington (U.S. Govt. Printing Office), 825-837.
Langseth, M.G., Mottl, M.J., Hobart, M.A., and Fisher, A., 1988. The distribution of geothermal and geochemical gradients near Site 501/504: implications for hydrothermal circulation in the oceanic crust. In Becker, K., Sakai, H., et al., Proc. ODP, Init. Repts., 111: College Station, TX (Ocean Drilling Program), 23-32.

Lister, C.R.B., 1970. Heat flow west of the Juan de Fuca Ridge. J. Geophys. Res., 75:2648-2654.

, 1972. On the thermal balance of a mid-ocean ridge. Geophys. J. R. Astron. Soc., 26:515-535.

, 1977. Estimates for heat flow and deep rock properties based on boundary layer theory. Tectonophysics, 41:157-171.

, 1979. The pulse-probe method of conductivity measurement. Geophys. J. R. Astron. Soc., 57:451-461.

Moran, J.E., and Lister, C.R.B. 1987. Heat flow across Cascadia Basin near $47^{\circ} \mathrm{N}, 128^{\circ}$ W. J. Geophys. Res., 92:11416-11432.

Mottl, M.J., 1989. Hydrothermal convection, reaction, and diffusion in sediments on the Costa Rica Rift flank: pore-water evidence from ODP Sites 677 and 678. In Becker, K., Sakai, H., et al., Proc. ODP, Sci. Results, 111: College Station, TX (Ocean Drilling Program), 195-213.

Parsons, B., and Sclater, J.G., 1977. An analysis of the variation of ocean floor bathymetry and heat flow with age. J. Geophys. Res., 82:803-827.

Robinson, S.W., 1997. Thermal conductivity, heat flow, and basement temperature on the eastern flank of the Juan de Fuca Ridge. [M.S. thesis]. Univ. Utah, Salt Lake City, UT.

Rohr, K., 1994. Increase of seismic velocities in upper oceanic crust and hydrothermal circulation in the Juan de Fuca plate. Geophys. Res. Lett., 21:2163-2166.

Sclater, J.G., Crowe, J., and Anderson, R.N., 1976. On the reliability of ocean heat flow averages. J. Geophys. Res., 81:2997-3006.

Snelgrove, S., and Forster, C.B., 1996. Impact of seafloor sediment permeability and thickness on off-axis hydrothermal circulation: Juan de Fuca Ridge eastern flank. J. Geophys. Res., 101:2915-2925.

Thomson, R.E., Davis, E.E., and Burd, B.J., 1995. Hydrothermal venting and geothermal heating in Cascadia Basin. J. Geophys. Res., 100:6121-6141.

Villinger, H., and Davis, E.E., 1987. A new reduction algorithm for marine heat flow measurements. J. Geophys. Res., 92:12846-12856.

Wang, K., He, J., and Davis, E.E., 1997. Influence of basement topography on hydrothermal circulation in sediment-buried igneous oceanic crust. Earth Planet. Sci. Lett., 146:151-164.

Wheat, C.G., and Mottl, M.G., 1994. Hydrothermal circulation, Juan de Fuca Ridge eastern flank: factors controlling basement water composition. $J$. Geophys. Res., 99:3067-3080.

Williams, D.L., Von Herzen, R.P., Sclater, J.G., and Anderson, R.N., 1974. The Galapagos spreading centre: lithospheric cooling and hydrothermal circulation. Geophys. J. R. Astron. Soc., 38:587-608.

Yang, J., Edwards, R.N., Molson, J.W., and Sudicky, E.A., 1996. Fractureinduced hydrothermal convection in the oceanic crust and the interpretation of heat-flow data. Geophys. Res. Lett., 23:929-932.

\section{Ms 168IR-102}




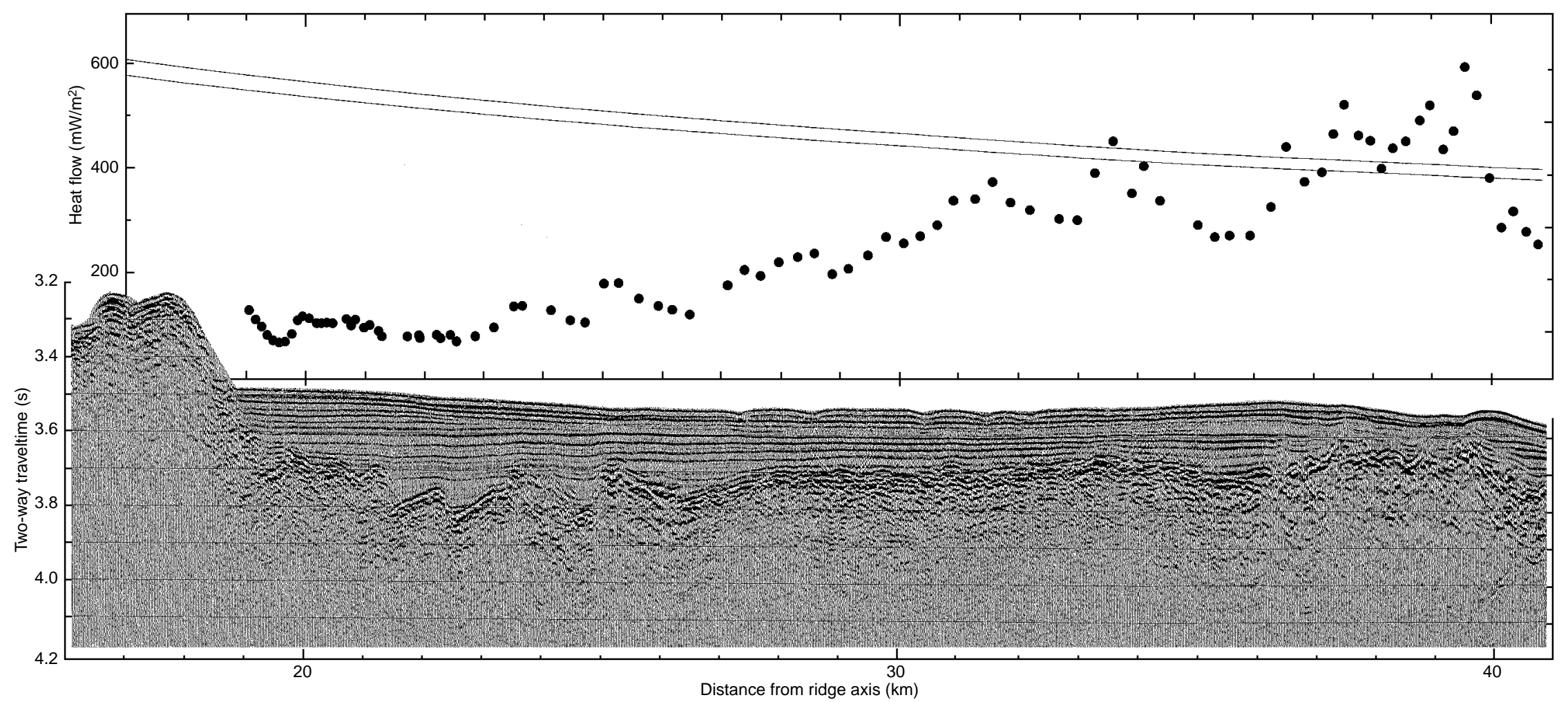

Figure 10. Heat-flow and seismic transect showing an increase of heat flow away from a region of extensive outcrop near the axis of the Juan de Fuca Ridge. Two theoretical lithospheric heat flow vs. age relationships (Lister, 1977; Parsons and Sclater, 1977) are shown for comparison. Cool seawater is inferred to circulate into the unsedimented permeable igneous crust near the ridge and advectively exchange heat laterally beneath the onlapping sediment cover. Estimated upper basement temperatures rise systematically from a few degrees near the outcrop to about $40^{\circ} \mathrm{C}$ about $20 \mathrm{~km}$ to the east.

\section{Previous Chapter}

\section{Next Chapter}

